\title{
Welke didactische aanpak voor vt-vertaalcolleges in het universitaire vreemdetalenonderwijs?
}

\begin{abstract}
During the last decade translation in foreign language teaching has experienced renewed interest. At present, research in this area focuses not so much on the advantages and disadvantages of translation, but on the question of how it can be optimally integrated and taught in higher education. We decided to look for an answer to that question in the didactics of translation and foreign language education. The result of our study is the teaching model that we present in this article. We also demonstrate how we applied this model during the practical FL-translation ${ }^{1}$ classes taught to third-year undergraduate students of the programme offered by the Dutch Chair of the John Paul II Catholic University of Lublin where translation is taught as part of the Dutch language learning programme.
\end{abstract}

Keywords: foreign language teaching, didactics of translation, higher education, teaching model.

\section{Inleiding}

Tijdens de laatste decennia staat het onderzoek naar de reïntegratie van vertalen in het universitaire tweede- en vreemdetalenonderwijs opnieuw in de belangstelling. Hierbij kunnen we ons afvragen of vertalen ooit uit dit soort onderwijs is verdwenen. In taalcursussen wordt vertaling namelijk nog steeds gebruikt als middel om de vaardigheid in de vreemde taal van studenten aan te leren en te beoordelen (Schjoldager 2004: 130 in Carreres \& Noriega-Sánchez 2011: 282). Niettemin concen-

${ }^{1}$ The abbreviation 'FL' stands for 'foreign language'. As such 'FL-translation' stands for translation into a foreign language. 
treerde het onderzoek in dit domein zich geruime tijd op de voor- en nadelen van vertalen in dit soort onderwijs. Opvallend is dat sinds 2001 het Gemeenschappelijk Europees Referentiekader voor Talen (ERK) de term 'bemiddeling', waaronder vertalen en tolken vallen, hanteert. Dit betekent dat vertalen thans door een (op het onderwijs invloedrijke) officiële instantie als de Raad van Europa als volwaardige taalactiviteit erkend wordt in het vreemdetalenonderwijs. Volgens het ERK kan vertalen wel degelijk als didactisch instrument worden ingezet om specifieke competenties, zoals interculturele vaardigheden en de communicatieve taalcompetentie, ${ }^{2}$ van taalleerders te bevorderen. Tevens wijzen experts in een onderzoek naar de rol van vertalen in het taalonderwijs in de Europese Unie - dat in 2013 werd verricht door het Directoraat-generaal Vertaling van de Europese Commissie - op het belang om vertaling te beschouwen als een vorm van communicatie en mediatie (Pym e.a. 2013: 139). Ook al blijkt uit dit onderzoek dat vertalen in heel wat Europese landen tijdens vreemdetaallessen wordt toegepast, wordt het niet uitdrukkelijk vermeld in de officiële curricula. Toch blijken experts op het gebied van vreemdetalenonderwijs (VTO) en vertalen ervan overtuigd dat vertalen kan bijdragen tot de bevordering van de linguïstische en interculturele competentie van taalleerders. Aangezien volgens hen vertalen kan worden beschouwd als "a goal-driven communicative activity (...) able to produce interactive knowledge about languages and culture" (Рym e.a. 2013: 139), rijst hier dan meteen ook de vraag in hoeverre de plaats en rol van vertaling in het VTO niet 'officieel' zou moeten worden herzien. Dit geldt vooral voor de zogenaamde 'westerse traditie' [waar nog steeds de overtuiging heerst dat talen moeten aangeleerd worden zonder gebruik te maken van de moedertaal (T1) van de leerders]. Aan universiteiten met een faculteit in taal- en letterkunde in de meeste landen van Centraal-Europa zien we daarentegen dat het vertaalonderwijs gewoon een onderdeel vormt van een taal(verwervings)cursus. De leerstoelen Nederlands in Polen zijn hier een voorbeeld van. De situatie is anders in het westen doordat met de opkomst van de communicatieve methode - een 'westers product' - in het taalonderwijs in de jaren 70 en 80 vertalen sterk onder vuur kwam te liggen en als contraproductief beschouwd werd in het taalverwervingsproces (Colina 2003: 2). Desondanks heeft de toenemende belangstelling voor de interculturele en communicatieve dimensie in zowel de vertaalwetenschap als in het vreemdetalenonderwijs ervoor gezorgd dat vertalen in het VTO sinds medio 1990 ook in het westen wordt geherwaardeerd. Voorstanders van het integreren van het vertaalonderwijs in het taalcurriculum suggereren hierbij dat vertalen de taalvaardigheid van de leerders in de hand kan werken, vooral wanneer de nadruk wordt gelegd op de communicatieve dimensie en op aspecten die relevant zijn voor de beroepspraktijk (Peverati 2009 volgens Fraser 1996 en Sewell 1996).

${ }^{2}$ Communicatieve taalcompetenties zijn die welke iemand in staat stellen te handelen gebruik makend van specifiek talige middelen (ERK 2008, 13). Communicatieve taalcompetentie omvat verscheidene elementen: linguïstische, sociolinguïstische en pragmatische. Elk van deze elementen wordt verondersteld kennis, vaardigheden en bekwaamheden te omvatten (ERK 2008, 16). 
Op dit ogenblik focust het onderzoek gerelateerd aan de (re)integratie van vertalen in het VTO zich niet meer zo zeer op de voor- en nadelen van vertalen (= het nut), maar op de vraag naar de manier waarop het optimaal kan worden geïntegreerd in de vreemdetaalles (= de aanpak). Hierbij is vooral sprake van t1vertalen of vertalen naar de eerste taal, maar ook van $\mathrm{t} 2$ - en vt-vertalen of vertalen naar de tweede en/of vreemde taal ${ }^{3}$ die het onderwerp vormt van dit artikel.

Omdat ik zelf vt-vertaalcolleges geef aan derdejaarsstudenten in een bacheloropleiding en zelf nood had aan een heldere en betrouwbare methodologische aanpak, besloot ik om op zoek te gaan naar een aanpak. Op mijn zoektocht naar een geschikte methode ontdekte ik dat tegenwoordig niet alleen in het taal- en vreemdetalenonderwijs de communicatieve en interculturele communicatieve dimensie een cruciale rol spelen, maar ook in het vertaalonderwijs en de vertaalwetenschap, in het bijzonder in de functionalistische vertaalbeschouwing die ontwikkeld werd voor een praktische vertaaldidactiek. Daarom besloot ik te onderzoeken in hoeverre de didactische inzichten (gerelateerd aan de bevordering van de interculturele competentie en de communicatieve taalcompetenties) van beide domeinen met elkaar verenigd kunnen worden.

Het resultaat van mijn zoektocht is een didactisch model dat ik in het eerste semester van het academiejaar 2016-17 heb uitgetest in de vt-vertaalcolleges die ik geef in het derde jaar van de bacheloropleiding van de Leerstoel Nederlands van de Katholieke Johannes Paulus II Universiteit te Lublin. Uit die toetsing is onmiddellijk gebleken dat het oorspronkelijke model (model 1) moest worden aangepast. ${ }^{4}$

In dit artikel wordt uiteengezet hoe model 1 werd getoetst en geamendeerd. Bovendien wordt model 2 - oftewel de geamendeerde versie van model 1 - gepresenteerd. Aan de hand van een concreet voorbeeld zal ik aantonen waarom en hoe ik model 1 heb gewijzigd.

Volgens de internationaal erkende norm ISO 17100:2015 wordt het vertaalproces ingedeeld in drie fasen. Naast de eigenlijke vertaling (production process) bestaat ze uit een voorbereidende (pre-production phase) en een afsluitende fase (post-production phase). Model 1 werd geïmplementeerd en getoetst in de voorbereidende fase, omdat die garandeert dat de juiste vragen worden gesteld vooraleer de leerder aan de slag gaat met de eigenlijke vertaling van de tekst. Dankzij

${ }^{3}$ Het onderscheid tussen de begrippen 'tweede taal' (t2) en 'vreemde taal'(vt) is gebaseerd op het gebruik dat van de taal gemaakt wordt. Als een taal een secundair communicatiemiddel blijft naast de moedertaal, beschouwt men ze als een vreemde taal. Is ze daarentegen een dagelijkse gebruikstaal, een omgangstaal in een gemeenschap naast de moedertaal, dan beschouwt men ze als een tweede taal (Beheydt 1987: 6).

${ }^{4}$ Voor meer details over het ontstaan en de betekenis van de onderdelen van Model 1 en de didactische modellen van Nord (1991) en Van Kalsbeek (2008), verwijs ik naar het artikel "Bevordering van interculturele competentie in het universitaire vreemdetalenonderwijs" van Waterlot dat in 2016 werd gepubliceerd in Neerlandica Wratislaviensia 26: 181-199. 
het model worden de leerders dus bewuster gemaakt van de doelgroep van de vertaling en van de doelcultuur waarin hun vertaling moet functioneren. Bijgevolg zullen ze in de vertaalfase bewustere vertaalkeuzes maken, en een 'vertaalproduct afleveren' dat goed is afgestemd op de lezer en de doelcultuur. Het model kan naderhand ook toegepast worden tijdens een feedbacksessie, doordat het de docent in staat stelt om - samen met de leerders - de verschillende stappen van de voorbereidende fase nogmaals te doorlopen om te achterhalen waar er eventueel betere vertaalbeslissingen hadden kunnen worden genomen.

\section{Toetsing model 1}

\section{Voorbereidende fase}

In het eerste semester van het academiejaar 2016-17 heb ik model $1^{5}$ (cfr. fig. 1) getoetst in de vt-vertaalcolleges van het derde jaar van de bacheloropleiding van onze leerstoel.

\begin{tabular}{|c|c|c|c|}
\hline General & Openness & $\rightarrow$ & Attitude \\
\hline & Knowledge & $\rightarrow$ & Knowledge \\
\hline & Flexibility & $\rightarrow$ & Skills \\
\hline \multirow[t]{3}{*}{$\begin{array}{c}\text { Profession } \\
\text { oriented }\end{array}$} & $\begin{array}{l}\text { Perspective } \\
\text { Nord: stap } 1\end{array}$ & $\rightarrow$ & Attitude \\
\hline & $\begin{array}{c}\text { Context } \\
\text { Nord: stap } 2\end{array}$ & $\rightarrow$ & Knowledge \\
\hline & $\begin{array}{c}\text { Dialogue } \\
\text { Nord: stap } 3\end{array}$ & $\rightarrow$ & Skills \\
\hline
\end{tabular}

Figuur 1. Model 1: schematische voorstelling van een didactiek van geïntegreerd intercultureel vt-vertaalonderwijs

De colleges, waaraan 24 studenten deelnamen, vonden wekelijks plaats (1,5 uur per week en in totaal 30 uur per semester) in het kader van de taalverwervingscursus Nederlands en beoogden in de eerste plaats de communicatieve taalcompetentie en de interculturele (communicatieve) competentie van de taalleerders te bevorderen.

Bij het definiëren van de vertaaloefeningen stelde ik de volgende doelstellingen voorop:

${ }^{5}$ Dit model wordt gedetailleerd beschreven in het artikel „Bevordering van interculturele competentie in het universitair vertaalonderwijs van Waterlot” (2016). 
- Het bevorderen van de linguïstische vaardigheden bij de leerders;

- Het bevorderen van sociolinguïstische kennis van de doelcultuur;

- Het bevorderen van het bewustzijn dat vertalen een interculturele communicatieve activiteit is en bijgevolg een interculturele communicatieve competentie vraagt;

- Het nadenken over pragmatische factoren bij het vertalen van de brontekst (medium, tekstdoel/functie, doelgroep etc.);

- Het bespreken van vertaaloplossingen en -strategieën;

- Studenten bewust maken van het bestaan van verschillende mogelijke vertalingen.

In de lijn van Nord's aanpak werd elke vertaaloefening voorzien van een vertaalopdracht om de leerders bewuster te maken van de contextuele factoren. Door de introductie van een opdrachtgever, een vertaalopdracht en vertaaldoel (of functie die de tekst moet vervullen in de doelcontext) bij de te vertalen tekst werd het vertaalgegeven gecontextualiseerd en kon de transfercomponent een reële rol spelen.

Wat de keuze van de tekstsoorten betreft, selecteerde ik teksten die in aanmerking komen voor een zogenaamde 'instrumentele' vertaling. Nord (1997) onderscheidt namelijk twee soorten vertalingen: een vertaling als 'document' en een vertaling als 'instrument'. Een documentaire vertaling leunt dicht aan tegen de brontaal. Een instrumentele vertaling daarentegen functioneert als een nieuwe tekst in de doelcultuur. Bij dit soort vertalingen is de ontvanger er zich niet of nauwelijks van bewust dat het om een vertaling gaat. De nieuwe tekst kan dezelfde functies hebben als de doeltekst (zoals dit bijvoorbeeld het geval is bij de vertaling van een recept of een gebruiksaanwijzing) (Vandeweghe 2008: 149). Omdat in de vt-vertaalles ook de bevordering van de interculturele (communicatieve) competentie van de leerders wordt beoogd, werden dus tekstsoorten geselecteerd die in aanmerking komen voor een instrumentele of 'communicatieve vertaling' (Colina 2003: 10). ${ }^{6}$ Hiermee wordt bedoeld dat teksten vertaald worden om te communiceren met een doeltaallezer of, anders gezegd, om in de doelcultuur een bepaald communicatief doel te bereiken, bijvoorbeeld informeren, onderrichten of instrueren, overtuigen et cetera. De vertaler zal er dus vooral voor moeten zorgen dat de doeltekst of vertaling in de doelcultuur dezelfde communicatieve functie vervult als de brontekst in de broncultuur.

Tot de zogenaamde 'instrumentele' vertaling behoren bijvoorbeeld de vertaling van technische handleidingen, zakelijke correspondentie, instructiebrochures en reclame. In de huidige betekenis van het woord zijn de meeste soorten professionele vertaling instrumenteel. Dit zijn meestal teksten met een informatieve functie of een appellatieve functie die 'ontvanger-gericht' zijn (bijvoorbeeld advertenties en direct mailbrieven).

${ }^{6}$ Het onderwijzen van dit soort vertaling wordt 'communicative translation teaching' of 'communicatief vertaalonderwijs' genoemd. 
Voor de doeleinden van het communicatieve vertaalonderwijs is het belangrijk om de functie van een brontekst te onderscheiden. Reiss (1974) en Nord (1997) onderscheiden er minstens drie: (1) de referentiële/informatieve functie met de volgende subfuncties: informatieve subfunctie (bijv. een medisch rapport) en de didactische subfunctie (bijv. een geschiedenisboek); (2) de expressieve functie; (3) operatieve (of appellatieve) functie met de volgende subfuncties: de adverterende subfunctie (bijv. de ontvanger aanzetten tot het kopen van een bepaald product), de illustratieve subfunctie (bijv. om iemand te helpen een nieuw concept te begrijpen), de persuasieve/argumenterende subfunctie (bijv. een journalist die in een artikel pleit voor een bepaalde controversiële kwestie) en de directieve subfunctie (bijv. een keukenrecept) (Colina 2003: 14). Bijgevolg werd voor de toetsing van model 1 een tekst met een informatieve functie en een tekst met een persuasieve functie gebruikt. Dit zijn teksten met duidelijk herkenbare 'tekstuele functies'. Wat de genres betreft, opteerde ik voor een recept uit de Poolse keuken en een direct mailbrief, waarbij een recept een directieve (sub)functie heeft (cfr. door middel van instructies wordt beschreven hoe een bepaalde handeling of procedure uitgevoerd moet worden) en een directmailbrief een adverterende (cfr. de lezer wordt er aangezet om een bepaald product te kopen).

De eerste vertaaloefening bestond uit de vertaling van twee (typisch) Poolse keukenrecepten naar het Nederlands. De vertaalopdracht bij deze eerste oefening luidde als volgt: "Vertaal de onderstaande Poolse recepten naar het Nederlands. De recepten zijn afkomstig uit het kookboek 'Ewa Gotuje' en zijn bestemd voor de kookrubriek van het weekblad 'Libelle'voor huisvrouwen in Nederland'.

\section{Lesverloop met toepassing van model 1}

Hoe zag het lesverloop eruit met toepassing van model 1 ?

Voor de geleider 'perspectief' werd - in de lijn van stap 1 van het Nord-model en op basis van de vertaalopdracht - in een brainstormsessie klassikaal gereflecteerd over de functie of bedoeling (skopos) (bijv. informatief? appellerend?) van de vertaling in de doelcultuur, de doelgroep en eventuele andere contextuele factoren die invloed kunnen hebben op de keuze van vertaalstrategieën (medium, plaats van de publicatie). Dankzij deze oefening trachtte ik de leerder bewust te maken van de aanwezigheid van de lezer (doelgroep) van de vertaling en zijn cultuur. Op die manier kon hij (bewuster) zijn perspectief innemen.

Voor de geleider context kregen de leerders in de lijn van Nord (stap 2) de opdracht om een tekstexterne en -interne analyse van de brontekst te maken en elementen aan te duiden die volgens hen bijzondere aandacht vereisen bij het vertalen van de tekst naar de vreemde taal. Tekstexterne elementen houden verband met land/streek/stad, tijdstip en medium; tekstinterne met factoren als thematiek, 
inhoud, tekststructurering, non-verbale elementen (lay-outaspecten), woordgebruik (realia) en syntactische structuur.

\section{Moeilijkheden implementatie model en oplossing (model 2)}

Algauw bleek dat de studenten reeds bij de eerste vertaaloefening moeite hadden om aan te duiden welke elementen in de brontekst bij het vertalen bijzondere aandacht vereisen. Dit komt door het gebrek aan (voor)kennis betreffende de sociolinguïstische, tekstuele, linguïstische en pragmatische aspecten van de doelcultuur, en in het geval van de eerste vertaaloefening: Nederland.

Spontaan begon ik dus extra opdrachten (taken) te bedenken om de geleider 'context' meer te activeren. Zo kwam ik tot het inzicht dat de functionalistische aanpak in het vt-vertaalonderwijs in de voorbereidende fase moest worden ondersteund door aanvullende taken.

In mijn zoektocht naar het bestaan van een theoretische verantwoording van deze bevinding, kwam ik op het spoor van het onderzoek van de vertaalwetenschapper Defeng Li die in 2013 het model van de taakgerichte aanpak - die in de jaren 90 in het taalonderwijs ontwikkeld werd, in het verlengde van de communicatieve methode - heeft aangepast voor de vertalersopleiding, in het bijzonder voor professionele vertalingen in de zakelijke context (Li 2013). Volgens Van Kalsbeek is de taakgerichte aanpak een realisatie van het functionele taalonderwijs dat "uitgaat van de idee dat het doel van taalleren verder reikt dan alleen communiceren (...)" (Van Kalsbeek 2006: 79). De aanpak "ligt in het verlengde van de communicatieve benadering: niet langer vormen situaties en thema's de kern van taalonderwijs, maar taken, ontleend aan de doelsituaties (Van Kalsbeek 2006: 79). Dit vormt alvast een bewijs dat de taakgerichte aanpak verenigbaar is met het functionele vertaalmodel van Nord.

Volgens mij kan Li's model mits enige aanpassingen worden toegepast in vt-vertaalcolleges (of 'communicatieve vt-vertaalcolleges') in de context van taalverwervingscursussen van universitaire filologische opleidingen. Het model biedt niet alleen nuttige inzichten voor een didactische aanpak gerelateerd aan de voorbereidende fase van het vertaalproces, maar ook voor twee andere fasen, met name de production phase (of eigenlijke vertaling) en de afsluitende fase of postproduction phase.

Wat de voorbereidende fase van het vertaalproces betreft - die ons hier in het bijzonder interesseert - maakt Li in zijn lessen gebruik van een pretask waarin de docent instructies geeft voor het uitvoeren van de taak en samen met de studenten de voorwaarden/bepalingen analyseert die omvat zijn in een vertaalopdracht. Dit is precies hetzelfde wat Nord doet, dus wat dat betreft biedt Li's aanpak geen nieuwe inzichten. 
In Li's aanpak, met name in de notie van task cycle - een takencyclus waarmee de docent de bevordering van een of meerdere specifieke 'deelcompetenties' van de vertaalcompetentie (in ons geval van de linguïstische en interculturele competentie die ook deel uitmaken van de vertaalcompetentie) als leerdoel kan vooropstellen - vond ik een theoretische verantwoording voor het invoeren van extra taken voor de geleiders in model 1.

In Li's model komt duidelijk naar voren dat in de voorbereidende fase de interculturele competentie vooral wordt bevorderd. Aangezien dit ook van belang is in het taalonderwijs (en wegens de geringe extra- en intratekstuele kennis van vt-tekstsoorten van de leerders) kan in een vt-vertaalles voor de geleiders 'perspectief' en 'context' dus eenvoudigweg een pretask cycle worden ingevoerd.

Wanneer we dit principe invoeren in model 1 krijgen we het volgende schematische voorstelling:

\begin{tabular}{|c|c|c|c|}
\hline General & Openness & $\rightarrow$ & Attitude \\
\hline & Knowledge & $\rightarrow$ & Knowledge \\
\hline \multirow{2}{*}{$\begin{array}{c}\text { Profession } \\
\text { oriented }\end{array}$} & Flexibility & $\rightarrow$ & Skills \\
\hline & $\begin{array}{c}\text { Perspective } \\
\text { Nord: stap 1 }\end{array}$ & $\rightarrow$ & Attitude \\
& $\begin{array}{c}\text { Context } \mathbf{2}, \mathbf{3} \ldots \\
\text { Nord: stap 2 } \\
\text { Taak 1, 2, 3 ... }\end{array}$ & $\rightarrow$ & Knowledge \\
\hline & $\begin{array}{c}\text { Dialogue } \\
\text { Nord: stap 3 } \\
\text { Taak 1, 2, 3 ... }\end{array}$ & $\rightarrow$ & Skills \\
\hline
\end{tabular}

Figuur 2. Model 2: schematische voorstelling van een taakgericht communicatief vertaalonderwijs

De vetgedrukte elementen duiden op meerdere taken die deel uitmaken van de pretask-cylcus.

Ik besloot om niet alleen voor de geleider 'context' maar ook voor de geleider 'perspectief' een takencyclus in te voeren omdat die zich beperkt tot een klassikale analyse van de vertaalopdracht. Concreet betekent dit dat in de vertaalles omtrent het tweede keukenrecept (en later van de directmailbrief) de drie geleiders extra geactiveerd werden aan de hand van een pretask-cyclus.

Voor de geleider 'perspectief' kregen de studenten de volgende drie taken: taak 1 bestond uit een geleide groepsdiscussie van 5 minuten over de kookgewoontes van studenten en hun ideeën/kennis van kookrecepten in de doeltaal en 
cultuur (hebben ze al ooit iets gekookt met een recept uit Nederland of Vlaanderen?). Als tweede taak (taak 2) kregen ze de opdracht om als voorbereiding op de vertaaloefening keukenrecepten (parallelle teksten) te verzamelen op Vlaamse en Nederlandse 'culinaire websites'. Die moesten ze meebrengen naar de les. Tijdens de eerste les gingen ze in tweetallen na wat kenmerkend is voor een Nederlands en Vlaams keukenrecept op het gebied van woordenschat en woordgebruik, stijl, structuur, lay-out, zinsbouw en andere kenmerken zoals bijv. hoe gedetailleerd de instructies zijn. Die bevindingen noteerden ze op een werkblad. Taak 3 bestond uit de klassikale analyse van vertaalopdracht zelf en werd daarbij op dezelfde manier te werk gegaan als voor het eerste keukenrecept.

Voor de activering van de geleider 'context' kregen de studenten twee taken. Bij taak 1 werd hen gevraagd om in tweetallen de brontaaltekst te lezen en te vergelijken met de Nederlandse recepten, en eventuele verschillen te noteren op een werkblad.

Bij taak 2 moesten ze in tweetallen in de brontekst cultuurspecifieke termen, kooktermen en -zinnen aanduiden en vertalen, waarbij ze in tweetallen in functie van de vertaalopdracht de juiste 'vertaalbeslissingen' moesten maken. De vertalingen werden op het werkblad genoteerd.

De geleider dialoog kon na deze pré-takencyclus naderhand makkelijk worden geactiveerd in een groepsdiscussie over hun bevindingen en vertalingen.

Meteen werd de inhoud van de colleges zinvoller en leerrijker, wat ook is gebleken uit de positieve reacties uit een feedback-vragenlijst die de leerders na de takencyclus hebben ingevuld.

In de taakgerichte aanpak staat het begrip 'taak' centraal. Voorstanders van deze benadering beweren dat door het leggen van de nadruk op de taak (het doel) en niet op het instrument (de vreemde taal), de vreemde taal ongemerkt wordt aangeleerd: "(...) a task provides language learners a purpose for using the language other than manipulating language form" (Lee 2000: 4 in van Kalsbeek 2004: 2-3). Wanneer we deze bewering toepassen op de context van vt-vertaling, kunnen we stellen dat de leerder niet alleen onopgemerkt zijn taal- en cultuurkennis (knowledgde) verruimt, maar tevens onbewust bepaalde subcompetenties van de vertaalcompetentie (zie figuur 3) onder de knie krijgt zoals bijv. de strategische competentie, de instrumentele of zoekcompetentie, de extralinguïstische competentie (gerelateerd aan de kennis over de doelcultuur), de linguïstische competentie (cfr. bilingual subcompetence) enz.

In het tweede semester van hetzelfde academiejaar (2016-17) heb ik in mijn vt-vertaalcolleges de toepasbaarheid van model 2 getoetst op basis van een 'zakelijke case' die bestond uit een reeks gesimuleerde en hoofdzakelijk zakelijk vertaalopdrachten. Op die manier konden de leerders - in een weliswaar gesimuleerde beroepscontext - in de huid kruipen van een professionele vertaler. 


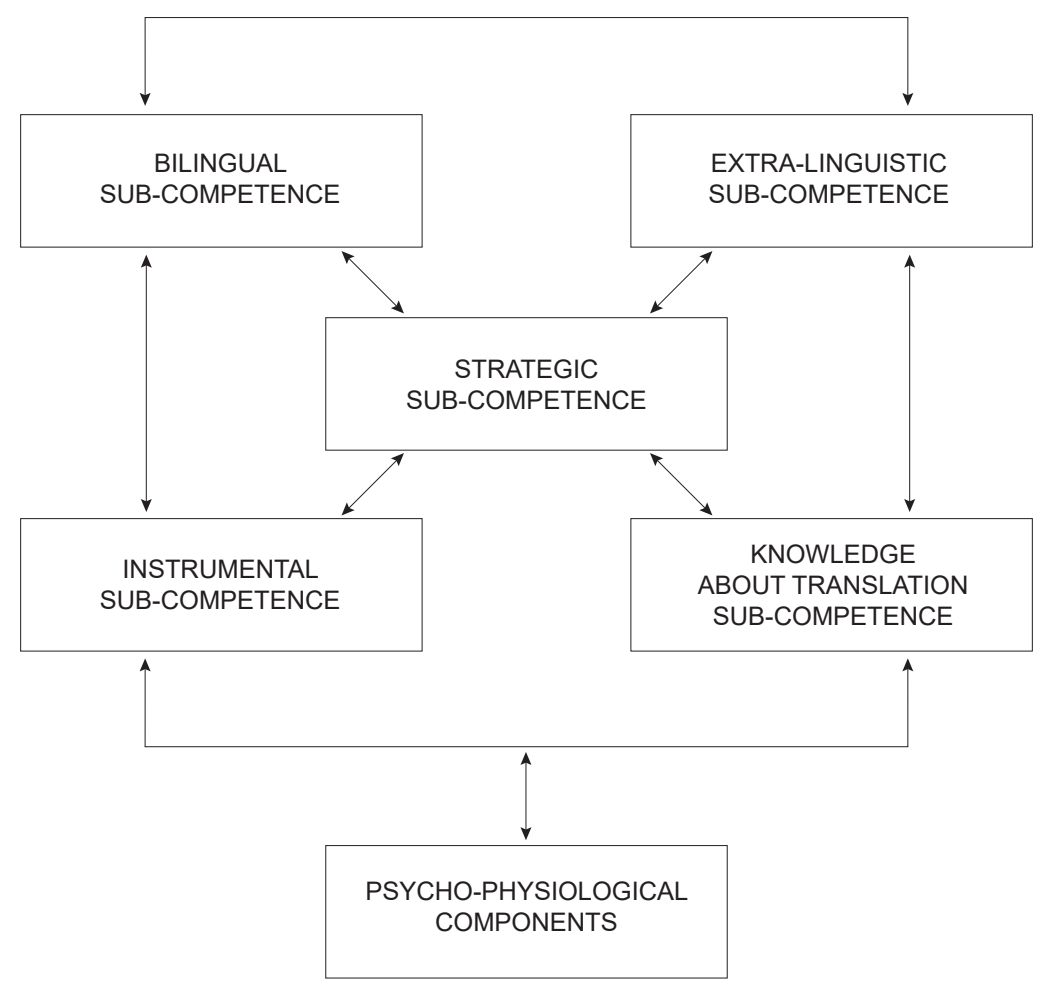

Figuur 3. Model vertaalcompetentie (PACTE 2005: 610) ${ }^{7}$

Ik opteerde voor zakelijke teksten omdat zakelijke en technische vertalingen thans het grootste deel uitmaken van het vertaalwerk dat door de industriële sector wordt opgedragen (Kingscott 1995; Venuti 1995 in Li 2013).

\section{Voordelen en uitdagingen van model 2}

Naast de verwerving van de communicatieve taalcompetentie en de interculturele vaardigheden van de leerders, zijn de vier aanvullende voordelen van model 2:

${ }^{7}$ Uit de vele modellen die er bestaan voor de omschrijving van de vertaalcompetentie die geconstrueerd zijn op basis van wetenschappelijke bevindingen van academici en als blauwdruk gebruikt worden bij het ontwerpen van vertaalcursussen, wordt het multicomponentieel model van de PACTE-onderzoeksgroep (Process of Acquisition of Translation Competence and Evaluation) vaak als model gebruikt. Hier hebben we te maken met een dynamische kijk op de vertaalcompetentie: afhankelijk van de context, kan een bepaalde subcompetentie een min of meer centrale plaats innemen. Deze kijk op vertaalcompetentie houdt ook in dat de vertaalcompetentie uitsluitend kan worden verworven als alle onderliggende competenties geactiveerd worden. 
1. Leerdergericht onderwijs;

2. Aandacht voor het vertaalproces (en niet alleen voor het vertaalproduct);

3. Bevordering van interculturele communicatieve competentie van de taalleerder;

4. Bevordering van subcompetenties van de vertaalcompetentie van de taalleerder.

Model 2 vormt een uitdaging voor de docenten:

1. De docent wordt begeleider in het leerproces van zowel taal als vertaling wat niet vanzelfsprekend is voor alle docenten. Sommige docenten zijn namelijk meer vertrouwd met de rol van kennisoverdrager.

2. Het ontwerpen van gesimuleerde taken is veeleisender dan het ontwerpen van een traditionele vertaalopdracht en vergt een zekere dosis aan creativiteit.

\section{Conclusie}

In de titel van dit artikel stelde ik de volgende vraag: "Welke didactische aanpak voor VT-vertaalcolleges in het universitaire vreemdetalenonderwijs". Uit mijn onderzoek is gebleken dat een taakgerichte communicatief vertaalonderwijs een antwoord biedt. Dit soort onderwijs berust op een combinatie van methodes uit zowel de vertaaldidactiek als de vreemdetaaldidactiek die hetzelfde doel nastreven: de bevordering van de communicatieve taalcompetentie en de interculturele vaardigheden van de leerders.

Deze aanpak vormt echter een uitdaging, voor taalleerder en docent doordat de leerder in de huid moet kruipen van een professionele vertaler, en de docent een creatieve begeleider moet worden in zowel het taal- als vertaalonderwijs. Dit vergt van beiden een zekere dosis openheid en creativiteit. Laat dit in ieder geval een boeiend en tevens leerrijk avontuur worden voor hen die deze uitdaging aangaan.

\section{Bibliografie}

Beheydt, Ludo (1987): "Het Certificaat Nederlands en Nederlands als Tweede Taal”. Voortzetten 7, Groningen: Wolters-Noordhoff.

Beheydt, Ludo (2003): "Cultuur in vreemdetalenleergange". In: Cornelia Carolina van Baalen, Ludo Beheydt \& Alice van Kalsbeek, Cultuur in taal. Interculturele vaardigheden voor docenten Nederlands aan anderstaligen. Utrecht: Nederlands Centrum Buitenlanders, 61-102.

Byram, Michael (2009): "The intercultural speaker and the pedagogy of foreign language education”. In Darla K. Deardorff (ed.), The SAGE Handbook of Intercultural Competence. Thousand Oaks, CA: Sage, 321-332.

Carreres, Angeles, \& María Noriega-Sanchez (2011): “Translation in language teaching: Insights from professional translator training". The Language Learning Journal 39:3, 281-297.

Colina, Sonia (2003): Translation Teaching, From Research to the Classroom: A Handbookfor Teachers. Singapore: McGraw-Hill Companies, Inc. 
Deardorff, Darla K. (2006): "Identification and assessment of intercultural competence as a student outcome of internationalization of higher education in the United States". Journal of Studies in International Education 10:3, 241-266.

EMT expert group (2009): Competences for Professional Translators, Experts in Multilingual and Multimedia Communication, laatst geraadpleegd op 10.07.2016 <http://ec.europa.eu/dgs/ translation/programmes/emt/key_documents/emt_competences translators en.pdf $>$.

(ERK) Meijer, Dick, \& Jose Noijons (2008): Gemeenschappelijk Europees Refentiekader voor Moderne Vreemde Talen: Leren, Onderwijzen, Beoordelen. Den Haag: Nederlandse Taalunie, laatst geraadpleegd in december $2017<$ http://taalunieversum.org/sites/tuv/files/downloads/gemeenschappelijk_europees_referentiekader.pdf $>$.

Kalsbeek, Alice van (2003): "Taal en cultuur of cultuur en taal”. In: Cornelia Carolina van Baalen, Ludo Beheydt \& Alice van Kalsbeek, Cultuur in taal. Interculturele vaardigheden voor docenten Nederlands aan anderstaligen. Utrecht: Nederlands Centrum Buitenlanders, 61-102.

Kalsbeek, Alice van (2004): Van communicatie naar competentie Recente benaderingen in het onderwijs Nederlands als tweede/vreemde taal. Steunpunt Nederlands als vreemde taal, http:// www.snvt.org/files/0704_AvK.pdf.

Kalsbeek, Alice van (2006): "Grammatica in functioneel taalonderwijs". Praagse perspectieven 4, $75-86$.

Li, Defeng (2013): "Teaching business translation: A task-based approach". The Interpreter and Translator Trainer 7:1, 1-26.

Munday, Jeremy (2012): Introducing Translation Studies: Theories and Applications, $3^{\text {rd }}$ ed. London/New York: Routledge.

Nord, Christiane (1991): Text Analysis in Translation: Theory, Methodology, and Didactic Application of a Model for Translation-Oriented Text Analysis. Amsterdam/NewYork: Rodopi.

Nord, Christiane (1997): Translating as a Purposeful Activity: Functionalist Approaches Explained. Manchester, UK: St. Jerome Pub. Harvard.

PACTE group (2005): "Investigating translation competence: Conceptual and methodological issues". Meta 50:2, 609-619.

Peverati, Costanza (2009): "Professionally-oriented translation teaching in a foreign language faculty". Paper delivered at the conference "New Research in Translation and Interpreting Studies 2", Universitat Rovira i Virgili, Tarragona. In: Anthony Pym \& Alexander Perekrestenko (eds.), Translation Research Project 2. Tarragona: Intercultural Studies Group, 173-189.

Pym, Anthony, Kirsten Malmkjær \& Mar Gutiérrez-Colon Plana (2013): Translation and Language Learning: The Role of Translation in the Teaching of Languages in the European Union: A Study. Luxembourg: European Commission, DOI: https://doi.org/10.2782/13783.

Reiss, K. (1974): “Zur Bestimmungs des Schwierigkeitsgrades von Übersetzungen”. Mitteilungsblatt för Dolmetscher und Übersetzer 3, 1-6.

Vandeweghe, Willy (2008): Duoteksten: inleiding tot vertaling en vertaalstudie. Gent: Academie Press.

Vermeer, Hans Josef (2001): "Didactics of translation”. In: Mona Baker (ed.), The Routledge Encyclopedia of Translation Studies. London/New York: Routledge, 60-62.

Waterlot, Muriel, (2016): "Bevordering van interculturele competentie in het universitair vertaalonderwijs". Neerlandica Wratislaviensia 26, 181-199.

\section{Geraadpleegde websites}

Website internationale Organisatie voor Standaardisatie: International Organization for Standardization, "About ISO", laatst geraadpleegd op 25.03.2016<http://www.iso.org/iso/home/about. htm>.

Neerlandica Wratislaviensia 28, 2018

(C) for this edition by CNS 